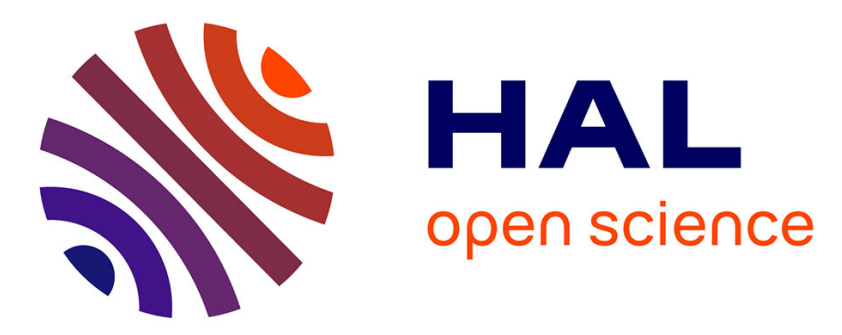

\title{
Regional numerical modelling of offshore monopile wind turbine impacts on hydrodynamics and sediment transport
}

\author{
Aurélie Rivier, Anne-Claire Bennis, Grégory Pinon, Markus Gross, Vanessa \\ Magar
}

\section{To cite this version:}

Aurélie Rivier, Anne-Claire Bennis, Grégory Pinon, Markus Gross, Vanessa Magar. Regional numerical modelling of offshore monopile wind turbine impacts on hydrodynamics and sediment transport. Guedes Soares, C. Renewable Energies Offshore, CRC Press, pp.807-813, 2015, 978-1-138-02871-5. 10.1201/b18973-114 . hal-01534087

\section{HAL Id: hal-01534087 \\ https://hal.archives-ouvertes.fr/hal-01534087}

Submitted on 6 Jan 2022

HAL is a multi-disciplinary open access archive for the deposit and dissemination of scientific research documents, whether they are published or not. The documents may come from teaching and research institutions in France or abroad, or from public or private research centers.
L'archive ouverte pluridisciplinaire HAL, est destinée au dépôt et à la diffusion de documents scientifiques de niveau recherche, publiés ou non, émanant des établissements d'enseignement et de recherche français ou étrangers, des laboratoires publics ou privés. 


\title{
Regional numerical modelling of offshore monopile wind turbine impacts on hydrodynamics and sediment transport
}

\author{
A. Rivier \& A.C. Bennis \\ Laboratoire de Morphodynamique Continentale et Côtière, UMR CNRS 6143 M2C, Université de Caen \\ Basse-Normandie, Caen, France \\ G. Pinon \\ Laboratoire Ondes et Milieux Complexes, UMR CNRS 6294 LOMC, Université du Havre, Le Havre, France \\ M. Gross \& V. Magar \\ Departamento de Oceanografía Física, CICESE, Ensenada, B.C., México
}

\begin{abstract}
Our purpose is to find a parameterization which is able to represent properly the modifications caused by wind turbine foundations on the hydrodynamics and sediment transport at regional scales. As a case study, the regional hydro-sedimentary model MARS3D is applied on an area including the future offshore wind farm of Courseulles-sur-Mer (Normandy, France). Wind turbines are represented using two approaches: the first method takes into account monopiles directly in the mesh as dry cells and the second one uses a sub-grid parameterization method by adding drag force term in momentum equations and source terms in k-turbulence model equations. Comparisons between the results obtained by the different approaches are carried out. As expected, both show impacts on the circulation, with formation of a wake downstream, flow deceleration in front of the pile, and flow acceleration at the side edges. Resuspension occurs in locations where current speeds increase due to the monopile presence.
\end{abstract}

\section{INTRODUCTION}

The construction of several offshore wind farms in the English Channel is planned in the coming years. They will be located both along French and English coasts (projects offshore of Saint-Brieuc, Fécamp, Courseulles-sur-Mer, Isle of Wight and Hasting). Although no wind turbines are present in the English Channel at the moment, they are numerous in the North Sea, where their impacts on sediment transport have been observed in a number of studies (e.g. CEFAS 2006, Department of Energy and Climate Change 2008, Vanhellemont and Ruddick 2014). The effects of offshore monopiles on local hydrodynamics have been evaluated in environmental impact studies using analytical expressions of drag (e.g. DHI 1999), or with finite element models in two dimensions (e.g. Actimar 2013). The first approach is simplistic, and the second one doesn't solve the vertical structure of velocity and therefore the nearbed velocity, which plays a key role for sediment transport. The aim of this work is to estimate monopile impact on the hydrodynamics and sediment transport in three dimensions in regional models like MARS Lazure and Dumas (2008). In these models, the typical spatial resolution allowing for reasonable calculation time is too coarse for explicitly incorporating the monopiles at a regional scale. The first step, described in this paper, consists in evaluating the impacts using the regional circulation model MARS 3D with a higher spatial resolution in a small area. The first strategy explicitly solves the wind turbine and the second one is based on a subgrid parameterization of the wind turbine effects on the environment. The study focuses on the area of the future wind farm of Courseulles-surMer, where the bed is composed of sand and gravels and the water depth is between 20 and 30 meters (m). Currents induced by tide are strong, reaching speeds of 1 meter per second $(\mathrm{m} / \mathrm{s})$ during medium spring tides. The influence of waves is weaker in the wind farm site, because the area is protected against waves from the Atlantic Ocean by the Cotentin Peninsula. This paper presents preliminary results obtained with both strategies in a test-case having characteristics close to Courseulles-sur-Mer site. Then these methods are applied in the real case using nested ranks.

\section{MATERIALS AND METHODS}

\subsection{Model description}

\subsubsection{Hydrodynamical model}

The regional hydrodynamical model MARS3D (Lazure and Dumas 2008) is applied in this study. It 
solves the momentum equations under the Boussinesq and the hydrostatic approximation.

Vertical mixing is solved using the generic length scale formulation (Umlauf and Burchard 2003). The turbulence equations are the following:

$$
\begin{aligned}
\frac{\partial k}{\partial t}+u \frac{\partial k}{\partial x}+v \frac{\partial k}{\partial y}= & \frac{\partial}{\partial z}\left(\frac{\nu_{V}}{s_{k}} \frac{\partial k}{\partial z}\right)+P \\
& +B-\epsilon \\
\frac{\partial \psi}{\partial t}+u \frac{\partial \psi}{\partial x}+v \frac{\partial \psi}{\partial y}= & \frac{\partial}{\partial z}\left(\frac{\nu_{V}}{s_{\psi}} \frac{\partial \psi}{\partial z}\right) \\
+ & \frac{\psi}{k}\left(C_{1} P+C_{3} B-C_{2} \epsilon F_{\text {wall }}\right)
\end{aligned}
$$

where $k$ is the turbulent kinetic energy, $\psi$ is a generic length scale, $P$ and $B$ represent the effects of shear and buoyant production, $C_{1}, C_{2}, C_{3}, s_{k}, s_{\psi}$ are empirical constants. Buoyancy is neglected in this study $(B=0)$. For a $k-\epsilon$ turbulence model, they are adopted as follows $C_{1}=1.44, C_{2}=1.92, s_{k}=1, s_{\psi}=1.3$ and $F_{\text {wall }}$ is equal to 1 (Umlauf and Burchard 2003). Horizontal viscosity depends on the size of the mesh and it is expressed as:

$\nu_{H}=f_{\text {visc }} \cdot 0.01 \cdot \Delta y^{1.15}$

with $f_{\text {visc }}$ a coefficient ranging between 1 and 17 and $\Delta y$ being the size of the cell in y-direction.

As explained before, the influence of the monopile is taken into account using two methods. In the first one, the monopiles are solved explicitly. They are incorporated in the mesh and are treated as dry cells in the model. In the second one, the impact of the foundations on the environment is parameterized. The drag force exerted on the flow by the monopile is incorporated in the model by adding an extra source term in the momentum and turbulence equations. This second approach was already used to model the impact of vegetation on flow (Temmerman et al. 2005, Bouma et al. 2007, Baptist et al. 2007). The drag force per unit area, $\mathbf{F}_{\mathbf{d}}\left(F u_{d}, F v_{d}\right)$, induced by the monopile can be expressed in the $\mathrm{x}$ and $\mathrm{y}$ directions as:

$$
\begin{aligned}
& F u_{d}(z)=-\frac{1}{2} \frac{\rho_{0} C_{d} D}{\Delta x \Delta y}\left\|\mathbf{u}_{\infty}(\mathbf{z})\right\| u_{\infty}(z) \\
& F v_{d}(z)=-\frac{1}{2} \frac{\rho_{0} C_{d} D}{\Delta x \Delta y}\left\|\mathbf{u}_{\infty}(\mathbf{z})\right\| v_{\infty}(z)
\end{aligned}
$$

where $C_{d}$ is the drag coefficient, $D$ is the diameter of the pile, $\mathbf{u}_{\infty}\left(u_{\infty}, v_{\infty}\right)$ is the undisturbed current velocity upstream the pile, $\Delta x$ and $\Delta y$ are the size of the cell. These terms, divided by the density $\rho_{0}$, are added to the right hand side of momentum equations expressed in a Cartesian coordinates system.
The turbulence equations become:

$$
\begin{gathered}
\frac{\partial k}{\partial t}+u \frac{\partial k}{\partial x}+v \frac{\partial k}{\partial y}=\frac{\partial}{\partial z}\left(\frac{\nu_{V}}{s_{k}} \frac{\partial k}{\partial z}\right)+P-\epsilon \\
+\frac{\left\|\mathbf{u}_{\infty}(\mathbf{z})\right\|\left\|\mathbf{F}_{\mathbf{d}}(\mathbf{z})\right\|}{\rho_{0}} \\
\frac{\partial \psi}{\partial t}+u \frac{\partial \psi}{\partial x}+v \frac{\partial \psi}{\partial y}=\frac{\partial}{\partial z}\left(\frac{\nu_{V}}{s_{\psi}} \frac{\partial \psi}{\partial z}\right) \\
+\frac{\psi}{k}\left(C_{1} P-C_{2} \epsilon F_{\text {wall }}+C_{2} \frac{\left\|\mathbf{u}_{\infty(\mathbf{z})}\right\|\left\|\mathbf{F}_{\mathbf{d}}(\mathbf{z})\right\|}{\rho_{0}}\right)
\end{gathered}
$$

The distance between the pile and the location $\left(i_{\infty}\right.$, $j_{\infty}$ ) where the velocity is considered equal to $\mathbf{u}_{\infty}$ was determined using the dry points approach for a pile with a diameter of $6 \mathrm{~m}$ and input velocities ranging between 0.3 and $1.2 \mathrm{~m} / \mathrm{s}$. Velocities were considered undisturbed when they are superior or equal to $99 \%$ of the input velocity. Being based of these tests, the velocity is taken $90 \mathrm{~m}$ upstream the pile to estimate $\mathbf{u}_{\infty}$

\subsubsection{Sediment transport module}

The sediment transport module used in MARS 3D is described in Le Hir et al. (2011). It solves the following equation of advection-diffusion in the water column:

$$
\begin{aligned}
\frac{\partial C}{\partial t}+\nabla(\vec{v} C)= & \frac{\partial}{\partial x}\left(D_{H} \frac{\partial C}{\partial x}\right)+\frac{\partial}{\partial y}\left(D_{H} \frac{\partial C}{\partial y}\right) \\
& +\frac{\partial}{\partial z}\left(D_{V} \frac{\partial C_{i}}{\partial z}\right)+\frac{\partial w_{s} C}{\partial z}
\end{aligned}
$$

Erosion and deposition fluxes ( $\mathrm{E}$ and $\mathrm{D}$ respectively) are calculated following these formulations (Le Hir et al. 2011)

$$
\begin{aligned}
E & =E_{0}\left(1-\frac{\tau}{\tau_{c e}}\right)^{n} & & \text { if } \tau>\tau_{c e} \\
& =0 & & \text { if } \tau<\tau_{c e}
\end{aligned}
$$

where $E_{0}$ is a constant of erodability $\left(\mathrm{kg} \cdot \mathrm{m}^{-2} \cdot \mathrm{s}^{-1}\right), \tau$ is the bed shear stress, $\tau_{c e}$ is the critical shear stress for erosion and $n=1.5$.

$$
D=w_{s} C^{b}\left(1-\frac{\tau}{\tau_{c d}}\right)
$$

where $C^{b}$ is the concentration close to the bottom and $\tau_{c d}$ is the critical shear stress for deposition.

The critical shear stress for erosion and the settling velocity are calculated following Soulsby and Whitehouse (1997) and Soulsby (1997) respectively. $E_{0}$ is equal to $0.24 \mathrm{~kg} \cdot \mathrm{m}^{-2} \cdot \mathrm{s}^{-1}$ and $\tau_{c d}$ is equal to $1 \mathrm{~N} . \mathrm{m}^{-2}$. In this study only suspended sediment transport are considered. 


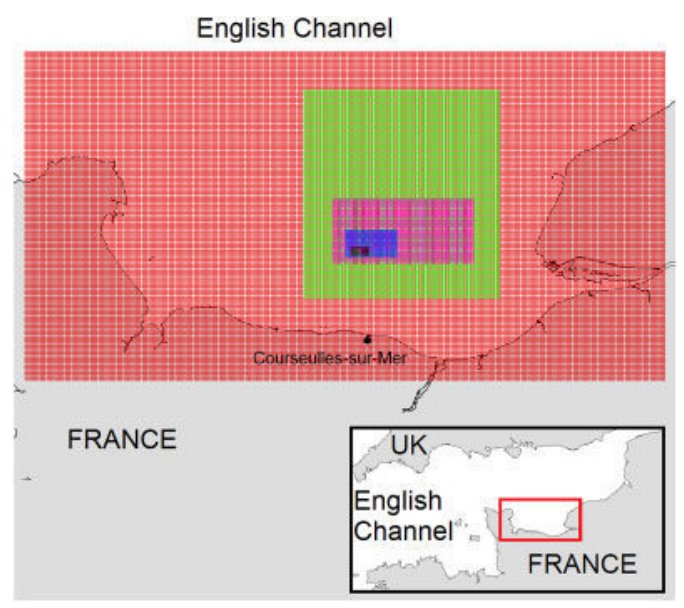

Figure 1. Calculation domains for the regional scale.

\subsection{Configurations}

\subsubsection{Hydrodynamic test-case}

The domain is a square of $600 \mathrm{~m}$ with a water depth of $30 \mathrm{~m}$. The horizontal resolution is $3 \mathrm{~m}$ and the water column is divided into 15 uniform layers. At the western boundary, sea surface heights vary periodically between 2 and $-2 \mathrm{~m}$ to reproduce a tidal current typical from the Courseulles-sur-Mer site. Zero velocity gradient are applied along the eastern and western boundaries, and periodic boundary conditions are used along the northern and southern boundaries. A pile with a diameter equal to $6 \mathrm{~m}$ is placed in the middle of the domain.

\subsubsection{Sediment test-case}

The domain, the vertical and horizontal resolutions, the water depth and the monopile are the same as those for the hydrodynamic test case. A constant eastward current of $0.6 \mathrm{~m} / \mathrm{s}$ is applied at the boundaries. The bed is composed of homogeneous sand with a diameter equal to $250 \mu \mathrm{m}$ which is present in the Courseullessur-Mer site.

\subsubsection{Courseulles-sur-Mer}

The regional model MARS3D is applied in a domain including the future offshore wind farm of Courseulles-sur-Mer (Fig. 1). Five nested ranks are used to allow a high resolution and take into account explicitly the monopile in the mesh. The horizontal resolutions are $243 \mathrm{~m}$ for rank 0 (red grid), $81 \mathrm{~m}$ for rank 1 (green grid), $27 \mathrm{~m}$ for rank 2 (pink grid), $9 \mathrm{~m}$ for rank 3 (blue grid) and $3 \mathrm{~m}$ for rank 4 (brown grid). The sea surface height is forced by data from SHOM (French Navy) for rank 0 and by data from the previous rank for the other ranks. Zero velocity gradients are imposed along open boundaries for rank 0. Dirichlet conditions are used for velocities for the other ranks. Only the rank 4 is solved in three-dimensions.

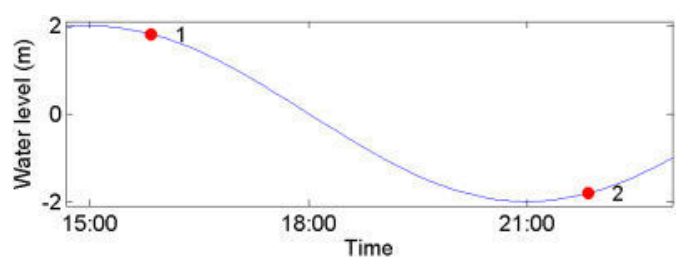

Figure 2. Sea surface height (m) during simulation.
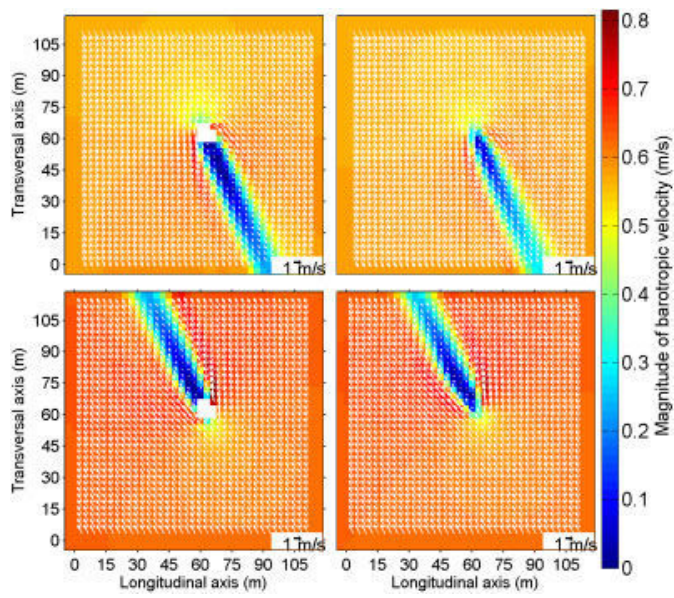

Figure 3. Magnitude $(\mathrm{m} / \mathrm{s})$ and direction of barotropic velocity for $\mathrm{t}=1$ (top) and $\mathrm{t}=2$ (bottom) with dry points approach (left) and parameterization approach (right).

\section{RESULTS}

\subsection{Hydrodynamic test-case}

The order of magnitude of Reynolds number is $10^{6}$. $C_{d}$ is chosen equal to 0.65 , compatible with the measurements made by Achenbach (1968) for this range of Reynolds numbers and the value taken by Rennau et al. (2012) in the Baltic Sea. $f_{\text {visc }}$ is taken equal to 1.5. The size of the mesh being uniform, the horizontal viscosity is also uniform. Figures 3 and 4 show the magnitude and the direction of the barotropic and the nearbed velocity respectively, just after the high and the low tide (times 1 and 2, respectively, in Fig. 2). The background velocity is higher at low tide than at high tide, as expected. With the dry points strategy, the barotropic and nearbed velocities increase on both sides of the monopile due to the contraction of the flow, and decrease upstream the monopile. These monopile effects are consistent with those described by Roulund et al. (2005). In front of the monopile, a horseshoe vortex is expected near the bed. Roulund et al. (2005) evaluated the size of this horseshoe vortex to be inferior to one time the diameter for a Reynolds number around $10^{6}$. With our spatial resolution of $3 \mathrm{~m}$, and a monopile with a diameter equal to $6 \mathrm{~m}$, this corresponds to less than two cells and is thus difficult to reproduce. Downstream of the monopile, the barotropic velocity becomes null. 

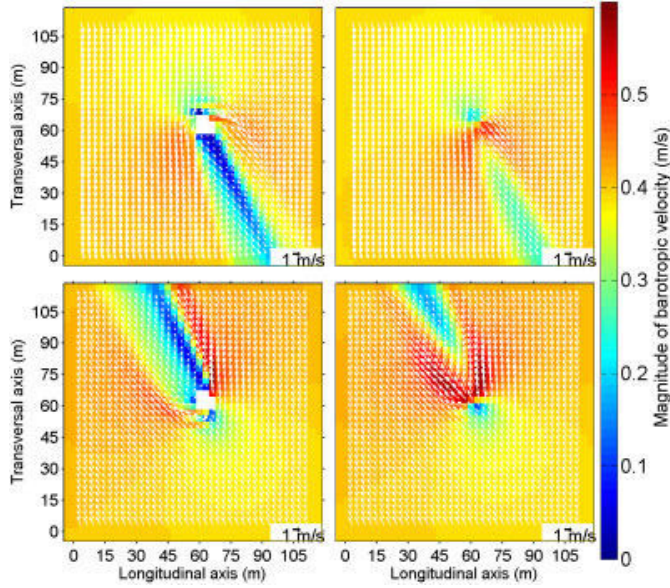

Figure 4. Magnitude ( $\mathrm{m} / \mathrm{s})$ and direction of nearbed velocity for $\mathrm{t}=1$ (top) and $\mathrm{t}=2$ (bottom) with dry points approach (left) and parameterization approach (right).

The pattern of barotropic velocity is reproduced with the parameterization. However, in the nearbed (Fig 4), the form of the wake behind the monopile is different between dry points method and parameterization in both cases. The velocity increases just behind the monopile, when it was expected to decrease.

Figures 5 and 6 present the turbulent kinetic energy (TKE) in the middle of the water column and in the nearbed, respectively. TKE increases around the monopile in both locations, especially upstream. This agrees with Dargahi (1989), who measured an increase of turbulence close to the bottom upstream of a cylinder, up to a distance equal to one diameter. Results from the simulations shown in figure 6 are consistent with these measurements.

The pattern and the intensity of TKE is similar between the dry points method and the parameterization in the middle of the water column for both times. At time 1 and 2, the nearbed TKE (Fig. 6) is stronger with the parameterization than with explicit method downstream close to the monopile, while it is weaker upstream of the monopile. This can explain the difference of velocity between the two methods visible at the top of figure 4 . In the middle of the water column TKE is overestimated by the parameterization at time 2 (see Fig. 5).

\subsection{Sediment test-case}

The sediment test-case is running with and without pile and the relative difference of the variable $\mathrm{X}$ is calculated following the expression $\frac{X_{p}-X_{s s p}}{X_{s s p}}$ where $X_{p}$ is the value of the variable obtained in the simulation with the monopile (dry point method or parameterization) and $X_{s s p}$ is the value of the variable obtained in the simulation without the monopile. Figure 7 shows the relative difference of sand concentration in the nearbed (top) and of bed shear stress (bottom) The pattern of the near bed concentration is closely linked with the

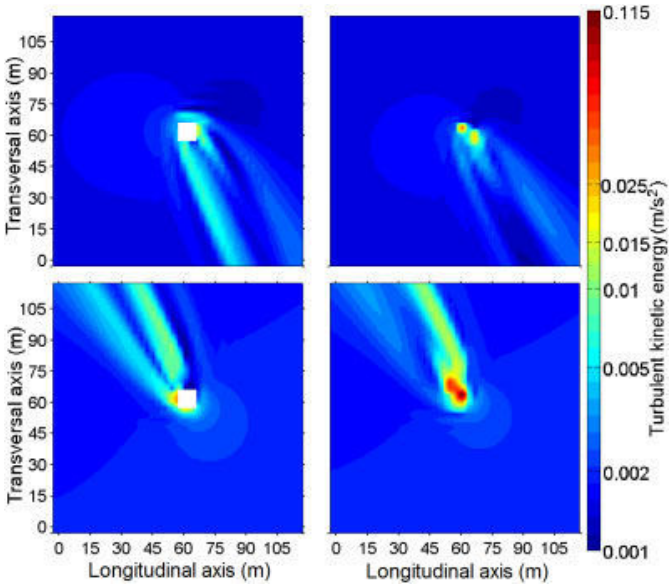

Figure 5. Turbulent kinetic energy $\left(\mathrm{m}^{2} \cdot \mathrm{s}^{-2}, \log \mathrm{scale}\right)$ in the middle of the water column for $t=1$ (top) and $t=2$ (bottom) with dry points approach (left) and parameterization approach (right).
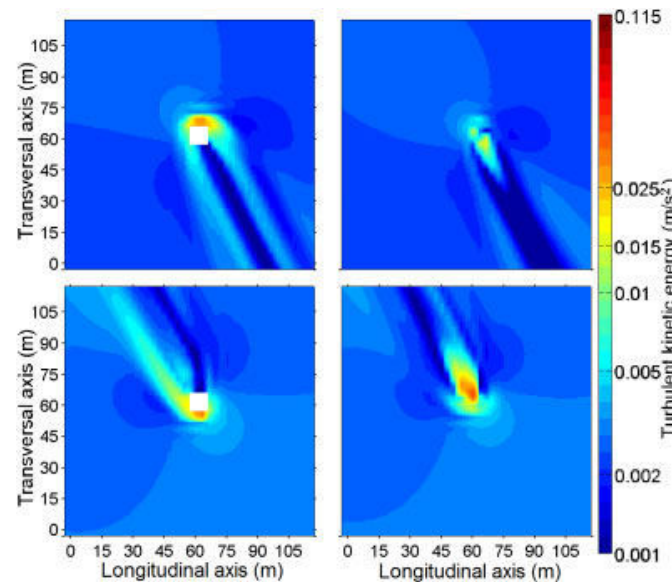

Figure 6. Turbulent kinetic energy nearbed $\left(\mathrm{m}^{2} \cdot \mathrm{s}^{-2}, \log \right.$ scale) for $\mathrm{t}=1$ (top) and $\mathrm{t}=2$ (bottom) with dry points approach (left) and parameterization approach (right).

distribution of the bed shear stress. The relative difference of the near bed concentrations of suspended sediment calculated with both methods are higher at the side edge, where the bed shear stress is stronger, and null downstream of the monopile, where the bed shear stress decreases in presence of a monopile and becomes lower than the critical bed shear stress for erosion. In front of the monopile, the sediment concentration and the bed shear stress decrease also when a monopile is present. This spatial distribution of bed shear stress is in agreement with Roulund et al. (2005) and Dargahi (1989). However, patterns are different between the dry point method and the parameterization method, especially in the immediate vicinity of the monopile. This difference is expected, due to the discrepancies in the nearbed velocities between the two methods, discussed in section 3.1. 


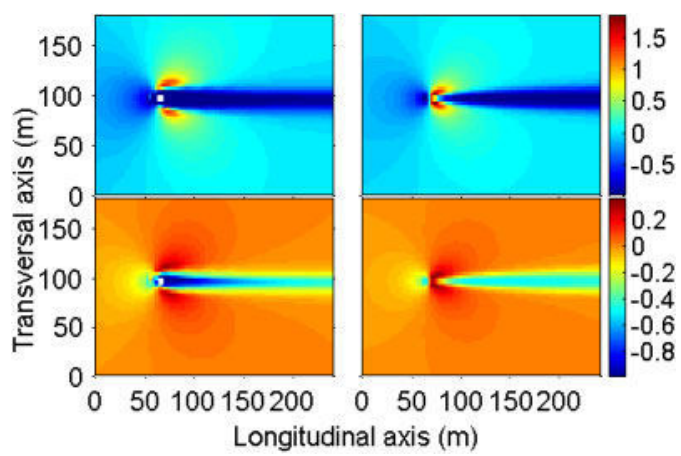

Figure 7. Relative difference of suspended sand concentration in the nearbed (top) and of bed shear stress (bottom) with dry points approach (left) and parameterization approach (right).

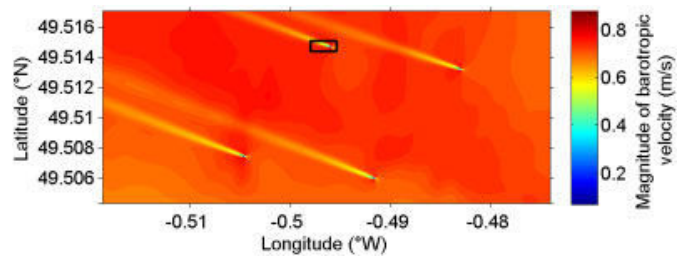

Figure 8. Magnitude of barotropic velocity $(\mathrm{m} / \mathrm{s})$ for Courseulles-sur-Mer site with dry points approach the $13 / 11 / 2011$ at $13: 45$. The rectangular frame indicates the area where the zoom is shown in figure 9 .

\subsection{Courseulles-sur-Mer}

Simulations are carried out on the 13/11/2011 when the tide is medium (tidal coefficient of 78). In the regional simulation case (with nested ranks), the horizontal viscosity had to be increased to avoid numerical instabilities. $f_{v i s c}$ is taken equal to 10 , leading to a uniform horizontal viscosity equal to $0.35 \mathrm{~m}^{2} / \mathrm{s}$ with a uniform spatial resolution. Figure 8 shows the magnitude of the barotropic velocity with the dry points approach, when it was close to its maximum value during the semi-diurnal tidal cycle. A wake appears downstream of each of the monopiles. A zoom is shown in figure 9 to analyse the pattern. With the dry points method (Fig. 9, top), the barotropic velocity decreases both in front and downstream of the monopile, but increases on the sides, in agreement with the results found in section 3.1. However, the decrease in velocity is smaller in this case than in the test-case (Fig. 3). This is due to the higher input horizontal viscosity used in this case. With the parameterization when the drag coefficient is still equal to 0.65 (Fig. 9 , middle), the spatial distribution of the barotropic velocity is reproduced but the impact is underestimated. The drag coefficient has to be increased to 1 (Fig. 9, bottom) to reach the same order of magnitude for the velocity in dry points method and parameterization method, while keeping the same pattern. The increase of the horizontal viscosity reduces and softens the effect of drag force on the flow. An artificial

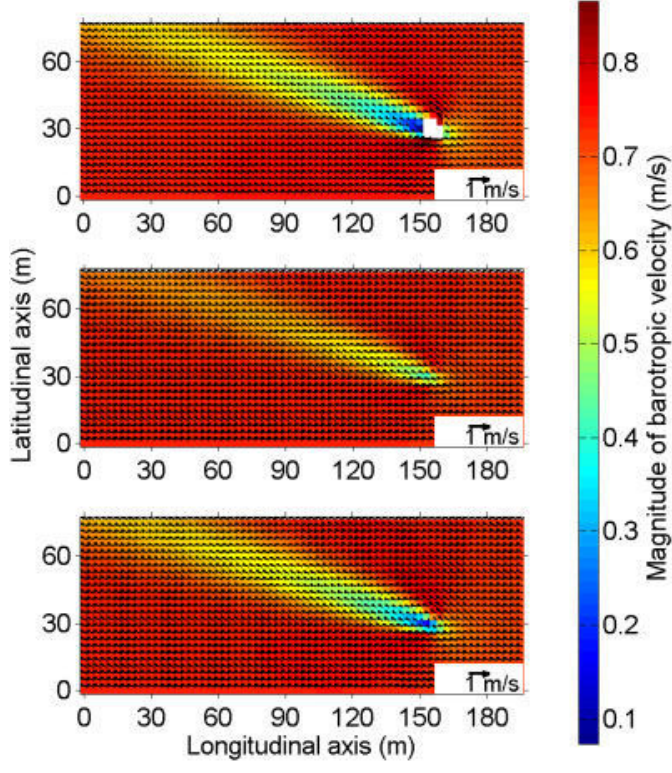

Figure 9. Zoom of the magnitude $(\mathrm{m} / \mathrm{s})$ and direction of barotropic velocity $(\mathrm{m} / \mathrm{s})$ the $13 / 11 / 2011$ at $13: 45$ for Courseulles-sur-Mer with dry points approach (top) and parameterization approach with $C_{d}=0.65$ (middle) and $C_{d}=1$ (bottom).

increase of $C_{d}$ is needed to produce the correct drag force.

\section{DISCUSSION}

The dry points strategy is considered here as the reference method. However, velocities obtained with this method still have to be validated. The width of the wake predicted with this method is compared with experimental measurements described in Baelhaq (2014), following a Froude similarity criterion. Figure 10 indicates that the intensity of the streamwise component of velocity across the flume near the surface is correctly reproduced. Additional laboratory experiments are being performed by project partners at the universities of Caen, Le Havre and Plymouth, in order to validate further the numerical modelling.

The drag coefficient $C_{d}$ is taken constant equal to 0.65 in the test case. The undisturbed velocity is around $0.6 \mathrm{~m} / \mathrm{s}$ at times shown. However, the parameterization either underestimates or overestimates the wake behind the monopile when velocities are lower and higher. This can be explained by the fact that $C_{d}$ is very sensitive for this range of Reynolds numbers (Achenbach 1968, Achenbach 1971, Roshko 1961). The values of the drag coefficient $C_{d}$, used in the parameterization method, should vary as a function of the Reynolds number, to improve results along an entire tidal cycle. The monopile shape and the flow direction also influence the drag coefficient (e.g. (Lindsey 1938)). 


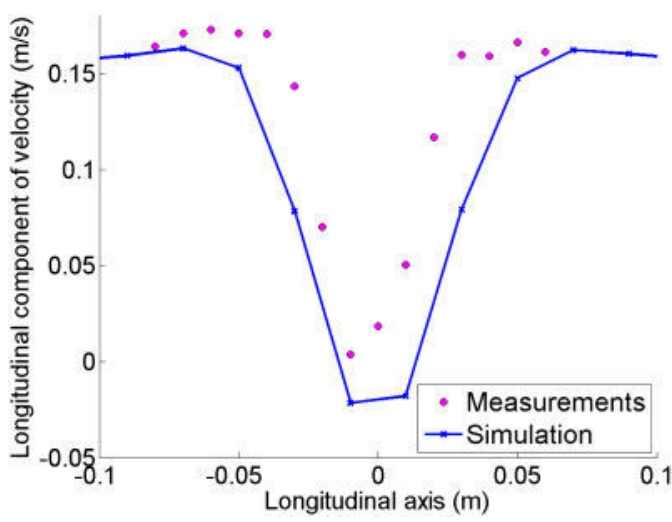

Figure 10. Streamwise component of velocity $(\mathrm{m} / \mathrm{s})$ across the flume near the surface simulated (blue line) and measured (pink points).

The parameterization method has difficulties in reproducing the pattern of the nearbed velocities around the monopile. At this location, complex structures, such as horseshoe vortices, are observed upsteam of the monopile. These vortices are well reproduced by Roulund et al. (2005), who solve explicitly the monopile and use a very high model resolution, with 128 cells all around the monopile. At present, the parameterization method developed here doesn't take into account this source of turbulence. However, as indicated in section 3.1, the size of the horseshoe vortex is less than one diameter (Roulund et al. 2005), so less than the size of two cells with the resolution used in our study. A sub-grid parameterization using a coarse grid is not able to reproduce horseshoe vortices.

The undisturbed (free stream) velocity is taken 90 $\mathrm{m}$ away from the monopile. However, in the regional model case, modifications of the current between this point and the monopile, due for instance to bathymetric changes, are not taken into account. This distance may be reduced in regional cases to calculate the drag force with an appropriate velocity.

Improvements of the parameterization method will help to reproduce the impact of a monopile on the hydrodynamics more accurately, especially at the bottom, and will lead to a better estimation of the sediment transport. Indeed, erosion and deposition are closely linked to the current velocity, and are key factors to evaluate the suspended sediment concentrations for this type of sand. For the regional case, the heterogeneity of the sediment, and the contributions of sediment discharges coming from rivers (Seine, Orne, Baie des Veys) or from coastal erosion (Velegrakis et al. 1999), will have to be considered.

\section{CONCLUSIONS}

In this paper two methods to assess monopile impacts on hydrodynamics and sediment transport were presented: a first approach explicitly solving the monopile, and a second approach where the effect of the monopile is included as a parameterization. The spatial distributions of velocity and TKE simulated with the first approach are in agreement with those published. The parameterization approach generally reproduces the velocity and TKE, but improvements are needed in the nearbed. It was observed that the choice of the drag coefficient for high Reynolds numbers requires further developments. Also, knowledge of the nearbed velocity around the monopile is essential to estimate local scour. Future work will consider the effect of waves on the monopile impacts, by coupling the circulation model MARS3D with the sea state model WW3 (Bennis et al. 2011).

\section{ACKNOWLEDGMENTS}

This paper is a contribution to the European crossborder program Interreg IVA France (Channel) - England OFELIA (Offshore Foundations EnvironmentaL Impact Assessments), which involves the universities of Caen, Le Havre and Plymouth. A. Rivier and G. Pinon are supported by the University of Le Havre, A.C. Bennis by the University of Caen and V. Magar and M. Gross by CICESE. A. Rivier acknowledges the support of a post-doctoral grant from the University of Le Havre. The authors are grateful to Frank Dumas (IFREMER) for providing the model configuration for the Courseulles-sur-Mer site and to Alexander Ezersky (University of Caen) for providing experimental data.

\section{REFERENCES}

Achenbach, E. (1968). Distribution of local pressure and skin friction around a circular cylinder in cross-flow up to $\mathrm{Re}=$ $5 \times 10^{6}$. Journal of Fluid Mechanics 34(04), 625-639.

Achenbach, E. (1971). Influence of surface roughness on the cross-flow around a circular cylinder. Journal of Fluid Mechanics 46(02), 321-335.

Actimar (2013). Synthèse de l'étude 2009 - Analyse des impacts hydrosédimentaires du projet de parc éolien en mer en Baie de Seine, rapport moc $\mathrm{N}^{\circ} 0732$ prepared for Eoliennes offshore du Calvados.

Baelhaq, A. (2014). Traitement des données expérimentales sur la synchronisation d'allée de Von Karman par les ondes superficielles. Master's thesis, Université de Caen Basse-Normandie.

Baptist, M., V. Babovic, J. Rodríguez Uthurburu, M. Keijzer, R. Uittenbogaard, A. Mynett, \& A. Verwey (2007). On inducing equations for vegetation resistance. Journal of Hydraulic Research 45(4), 435-450.

Bennis, A.-C., F. Ardhuin, \& F. Dumas (2011). On the coupling of wave and three-dimensional circulation models: Choice of theoretical framework, practical implementation and adiabatic tests. Ocean Modelling 40(3), 260-272.

Bouma, T., L. Van Duren, S. Temmerman, T. Claverie, A. Blanco-Garcia, T. Ysebaert, \& P. Herman (2007). Spatial flow and sedimentation patterns within patches of epibenthic structures: Combining field, flume and modelling experiments. Continental Shelf Research 27(8), 1020-1045.

CEFAS (2006). Scroby Sands Offshore Wind Farm - Coastal Processes Monitoring. Final Report AEO262 prepared for Marine Environmental Division, Defra and Department of Trade and Industry. 
Dargahi, B. (1989). The turbulent flow field around a circular cylinder. Experiments in Fluids 8(1-2), 1-12.

Department of Energy and Climate Change (2008). Review of Round 1 sediment process monitoring data - lessons learnt, Final Report.

DHI (1999). Horns Rev Wind Power Plant. Environmental impact assessment of hydrography. Report prepared for ELSAMPROJEKT.

Lazure, P. \& F. Dumas (2008). external-internal mode coupling for a 3D hydrodynamical model for applications at regional scale (MARS). Advances in Water Resources 31(2), 233-250.

Le Hir, P., F. Cayocca, \& B. Waeles (2011). Dynamics of sand and mud mixtures: a multiprocess-based modelling strategy. Continental Shelf Research 31(10), S135-S149.

Lindsey, W. (1938). Drag of cylinders of simple shapes. NACA.

Rennau, H., S. Schimmels, \& H. Burchard (2012). On the effect of structure-induced resistance and mixing on inflows into the Baltic Sea: A numerical model study. Coastal Engineering 60, 53-68.

Roshko, A. (1961). Experiments on the flow past a circular cylinder at very high Reynolds number. Journal of Fluid Mechanics 10(03), 345-356.

Roulund, A., B. M. Sumer, J. Fredsøe, \& J. Michelsen (2005). Numerical and experimental investigation of flow and scour around a circular pile. Journal of Fluid Mechanics 534, 351-401.
Soulsby, R. (1997). Dynamics of marine sands: a manual for practical applications. Thomas Telford.

Soulsby, R. \& R. Whitehouse (1997). Threshold of sediment motion in coastal environments. In Pacific Coasts and Ports' 97: Proceedings of the 13th Australasian Coastal and Ocean Engineering Conference and the 6th Australasian Port and Harbour Conference; Volume 1, pp. 145. Centre for Advanced Engineering, University of Canterbury.

Temmerman, S., T. Bouma, G. Govers, Z. Wang, M. De Vries, $\&$ P. Herman (2005). Impact of vegetation on flow routing and sedimentation patterns: Three-dimensional modeling for a tidal marsh. Journal of Geophysical Research: Earth Surface (2003-2012) 110(F4).

Umlauf, L. \& H. Burchard (2003). A generic length-scale equation for geophysical turbulence models. Journal of Marine Research 61(2), 235-265.

Vanhellemont, Q. \& K. Ruddick (2014). Turbid wakes associated with offshore wind turbines observed with Landsat 8. Remote Sensing of Environment 145, 105-115.

Velegrakis, A., D. Michel, M. Collins, R. Lafite, E. Oikonomou, J. Dupont, M. Huault, M. Lecouturier, J. Salomon, \& C. Bishop (1999). Sources, sinks and resuspension of suspended particulate matter in the eastern English Channel. Continental Shelf Research 19(15), 1933-1957. 